\title{
A Gastronomia brasileira na Copa do Mundo de Futebol da FIFA 2014: uma breve análise
}

The Brazilian gastronomy in the FIFA World Cup 2014: a brief analysis

\author{
Maria Henriqueta Sperandio Garcia Gimenes-Minasse \\ (MINASSE-GIMENES, M. H. S. G.)*
}

RESUMO - Este artigo constitui, a partir de revisões bibliográficas e pesquisa documental, uma breve reflexão sobre o potencial uso do patrimônio gastronômico brasileiro no contexto da Copa do Mundo de Futebol da FIFA 2014. Neste sentido, foram considerados não apenas o patrimônio gastronômico existente, mas também as ações voltadas para a qualificação da área e sua divulgação como atrativo turístico com destaque para a publicação 'Aroma, cores \& sabores do Brasil' (Ministério da Cultura, 2014). Verifica-se que poucas ações específicas foram realizadas e, às vésperas da realização do megaevento há poucos dados disponíveis, o que não permite uma avaliação acurada dos efeitos das ações realizadas.

Palavras-chave: Gastronomia; Megaeventos; Copa do Mundo 2014; Brasil.

ABSTRACT - This article constitutes a brief reflection, by means of bibliographical review and documental research, on the potential use of brazilian gastronomical heritage in the context of FIFA 2014 World Football Cup. For this purpose, it was considered not only the existing gastronomic heritage, but also the actions for its disclosure as a tourist attraction - especially the publication 'Aroma, colors \& flavors of Brazil' (Ministry of Culture, 2014). It was verified that few specific actions were taken, and on the eve of the mega event there are few available data, what do not permit an accurate assessment of the effects of actions accomplished.

Key words: Gastronomy; Mega events; World Cup 2014; Brazil.

\footnotetext{
"Formação: Graduação em Turismo (Bacharelado), Especialização em Planejamento e Gestão do Turismo, Mestrado em Sociologia e Doutorado em História pela Universidade Federal do Paraná (UFPR). Atividade profissional: Professora na Universidade Federal de São Carlos, Campus Sorocaba (UFSCAR). Endereço físico para correspondência: Rua Fausto Ferraz, 227, Bela Vista. CEP 01333-030. - São Paulo - SP (Brasil). Telefone para contato: 15 3222-3223. E-mail: mariegimenes@ gmail.com
} 


\section{INTRODUÇÃO}

O segmento Turismo de Esportes, conceituado pelo Ministério do Turismo (2012a, p. 23) como aquele que [...] "compreende as atividades turísticas decorrentes da prática, envolvimento ou observação de modalidades esportivas", vive um momento único no Brasil, atestado pela realização da Copa das Confederações da FIFA (Féderátion Internationale de Football Association) em 2013; da Copa do Mundo de Futebol da FIFA em 2014 e dos Jogos Olímpicos na cidade do Rio de Janeiro (RJ) em 2016.

Estes três eventos, por suas características e dimensões, são considerados megaeventos, expressão que, segundo Roche (1994), designa um acontecimento de curta duração, que demanda a criação de infraestrutura além de outras comodidades para a sua realização, e que garante resultados permanentes por longo tempo nas cidades e países sede. Eventos dessa natureza são captados com o objetivo de dinamizar a economia de um local, bem como projetar internacionalmente uma imagem positiva da localidade em questão. Em termos turísticos, os ganhos podem ser muitos, tendo em vista a potencialidade de divulgação do patrimônio turístico das localidades onde acontecem os eventos.

Em sua vigésima edição, a Copa do Mundo de Futebol da FIFA 2014 é, sem dúvida alguma, o megaevento de maior destaque. Estimativas do Grupo Executivo da Copa do Mundo 2014 do Governo Federal do Brasil, disponibilizadas no website Portal da Copa (website oficial do Governo Federal do Brasil sobre o evento), indicam que o megaevento agregará 183 bilhões de reais ao Produto Interno Bruto - PIB do país, mobilizando 33 bilhões de reais em investimentos em infraestrutura (com destaque para a área de transportes) e criando cerca de 700 mil empregos permanentes e temporários. (BRASIL, 2012d). Em termos de fluxos turísticos, a mesma fonte apresenta projeções de atração de aproximadamente 3,7 milhões de turistas (entre brasileiros e estrangeiros), que deverão movimentar no período cerca de R \$ 9,4 bilhões (BRASIL, 2012d).

Os impactos do evento poderão ser percebidos ao longo de todo o país, e de maneira mais direta nas 12 cidades-sede (cidades nas quais ocorrerão os jogos) e nas 32 cidades subsedes, que receberão as seleções para treinamento e concentração, 
espalhadas em 9 unidades federativas ${ }^{1}$. Diversas localidades serão beneficiadas não apenas por investimentos em infraestrutura e geração de empregos, mas também pela possibilidade de dinamizarem sua oferta turística, divulgando e consolidando atrativos inclusive gastronômicos - para visitantes estrangeiros ou não, que se deslocarão pelo Brasil durante o evento.

Traçado esse panorama, tem-se como objetivo geral deste artigo realizar uma breve reflexão, desenvolvida a partir de revisão bibliográfica e documental, sobre o potencial de divulgação do patrimônio gastronômico brasileiro como atrativo turístico durante a Copa do Mundo de Futebol da FIFA 2014. Tendo em vista que às vésperas do evento poucas ações específicas foram detectadas, dar-se-á destaque para a brochura bilíngue 'Aromas, cores e sabores do Brasil' lançada pelo Ministério da Cultura em junho de 2013 e destinada a jornalistas brasileiros e estrangeiros.

\section{RELAÇÕES ENTRE GASTRONOMIA E TURISMO}

A primeira e óbvia associação entre os serviços de alimentação e o turismo é a de saciação da necessidade fisiológica mais básica: nutrir-se. Já em 1825 Brillat-Savarin (1999) enaltecia a importância e a comodidade dos restaurantes para aqueles que estavam temporariamente privados de sua cozinha doméstica. Contudo, além da nutrição, há diversas outras associações, como a de agregar valor a outros serviços turísticos (como meios de hospedagem e meios de transporte, por exemplo), complementar a oferta de entretenimento de uma localidade (por meio de bares, restaurantes e casas noturnas), ou ainda se constituírem como atrativos turísticos propriamente ditos, o que revela a complexidade e proficuidade do relacionamento entre gastronomia e atividade turística.

Segundo Richards (2002) o patrimônio cultural tem ganhado relevância como um elemento estratégico de diferenciação na medida em que o nível de competitividade internacional entre destinos turísticos cresce. E, nesse contexto, entram em destaque as manifestações alimentares das localidades: "[...] not only because food is central to the tourist experience, but also because gastronomy has become a significant source of

\footnotetext{
${ }^{1}$ Os seguintes estados possuem cidades escolhidas como subsedes: Alagoas (1), Bahia (3), Espírito Santo (2), Paraná (2), Minas Gerais (3), Rio Grande do Sul (1), Rio de Janeiro (4), São Paulo (15), Sergipe (1).
}

Turismo \& Sociedade (ISSN: 1983-5442). Curitiba, v. 7, n. 1, p. 77-98, janeiro de 2014. Dossiê sobre Megaeventos. 
identity formation in postmodern societies" (RICHARDS, 2002, p. 3). Este movimento se dá no contexto de ascensão de um novo perfil de turistas, que segundo autores como Valls (2004), Chias (2005), Ejarque (2009) e Gândara, Gimenes e Mascarenhas (2008), desejam maior interação com o meio visitado, férias ativas e a vivência de experiências memoráveis. Para Urry (2001) as pessoas desejam experimentar em suas viagens prazeres distintos, que envolvem diferentes sentidos, que efetivamente ou não são estimulados no dia a dia, ou não são estimulados na intensidade desejada.

A ênfase na criação e vivência de experiências inesquecíveis remete à discussão feita por Pine II e Gilmore (1999) sobre a chamada economia da experiência. Nesta nova perspectiva, o foco do consumidor abandona os bens e os serviços e passa a se fixar na qualidade da experiência que pode ser vivenciada. As experiências, compreendidas como eventos capazes de envolver indivíduos de uma maneira pessoal, passam a ser buscadas nas mais diferentes esferas do consumo, cotidiano ou não (PINE II; GILMORE, 1999). Segundo Gândara, Gimenes e Mascarenhas (2008) o turista contemporâneo deseja deslocar-se para destinos nos quais possa viver, emocionar-se, ser o personagem de sua própria viagem. Deseja envolver-se nas experiências de maneira física e/ou mental, gerando uma demanda por produtos específicos e mais complexos, capazes de propiciar tal satisfação.

Os atrativos gastronômicos ganham relevância neste cenário, já que o ato alimentar engaja os cinco sentidos humanos (visão, olfato, tato, audição e paladar) em operações complexas capazes de produzir a sensação de gosto, envolvendo completamente o indivíduo. Ainda, o ato alimentar é também social, tendo em vista que as escolhas alimentares se fundam no mesmo arcabouço cultural que orienta as demais decisões de um grupo. É a partir desta premissa que se pode falar do consumo alimentar como um exercício identitário, por exemplo.

Assim, uma iguaria pode ser objeto de uma deliciosa degustação, mas também uma forma de conhecer ingredientes, formas de preparo, tradições e valores locais. É a partir desta perspectiva cultural que o patrimônio gastronômico ganha força e importância como atrativo turístico: quanto mais autêntico e ligado ao contexto visitado, maior será seu poder de atração. "Gastronomic experiences for tourists are usually developed from the perspective of 'unique' aspects of the gastronomy that can only be found in that particular occasion". (RICHARDS, 2002, p. 12). 
Desta forma, ingredientes, comidas e bebidas próprias de um local podem se tornar atrativos em bares, restaurantes e similares; festas e eventos gastronômicos; feiras livres; mercados públicos; e rotas e roteiros turísticos. Locais de produção de itens gastronômicos (vinícolas, alambiques, cervejarias, queijarias, apiários, dentre outros) também podem despertar o interesse de visitantes, contribuindo para o escoamento da produção e a divulgação do próprio produtor. Ainda, os próprios estabelecimentos podem se tornar um atrativo turístico por conta da reputação alcançada pelo chef, pela boa avaliação obtida em um guia gastronômico, pela temática desenvolvida, pela oferta de entretenimento associada, pela localização privilegiada, dentre outras características.

Independentemente da forma com que a gastronomia seja operacionalizada como atrativo turístico, o fato é que sua associação com outros atrativos (em especial a outros de caráter cultural) pode fortalecer em muito a oferta e a imagem de uma localidade, criando uma marca para um destino turístico e, por consequência, contribuindo para sua diferenciação em um mercado tão competitivo. Para Hall, Sharples e Mitchell (2003, p. 6) "[...] the very fact that food is expressive of a region and its culture has meant that it can be used as a means of differentiation for a destination in an increasingly competitive global marketplace”. Fields (2002, p. 43) defendendo que a gastronomia regional ou nacional é fundamental para uma destinação construir uma identidade forte: "[...] in an increasingly look-alike world, food with a strong national or regional identity can become one of the vehicles for achieving this".

Um evento como a Copa do Mundo de Futebol da FIFA 2014 - que voltará os olhos de milhões de pessoas para o Brasil - representa uma oportunidade praticamente única para a divulgação do patrimônio gastronômico brasileiro para residentes e estrangeiros.

\section{GASTRONOMIA BRASILEIRA : DIFERENCIAIS E POTENCIALIDADES PARA A COPA DO MUNDO DE FUTEBOL DA FIFA 2014}

Devido à sua diversidade geográfica e aos diferentes fluxos migratórios recebidos, o patrimônio gastronômico brasileiro é bastante diversificado, apresentando ingredientes e técnicas de preparo com características marcadamente regionais. Esta 
diversidade é contemplada pelas doze cidades-sede dos jogos da Copa do Mundo de Futebol da FIFA 2014 (todos elas também considerados destinos indutores ${ }^{2}$ pelo Ministério do Turismo), tendo em vista que elas encontram-se distribuídas pelas cinco grandes regiões brasileiras:

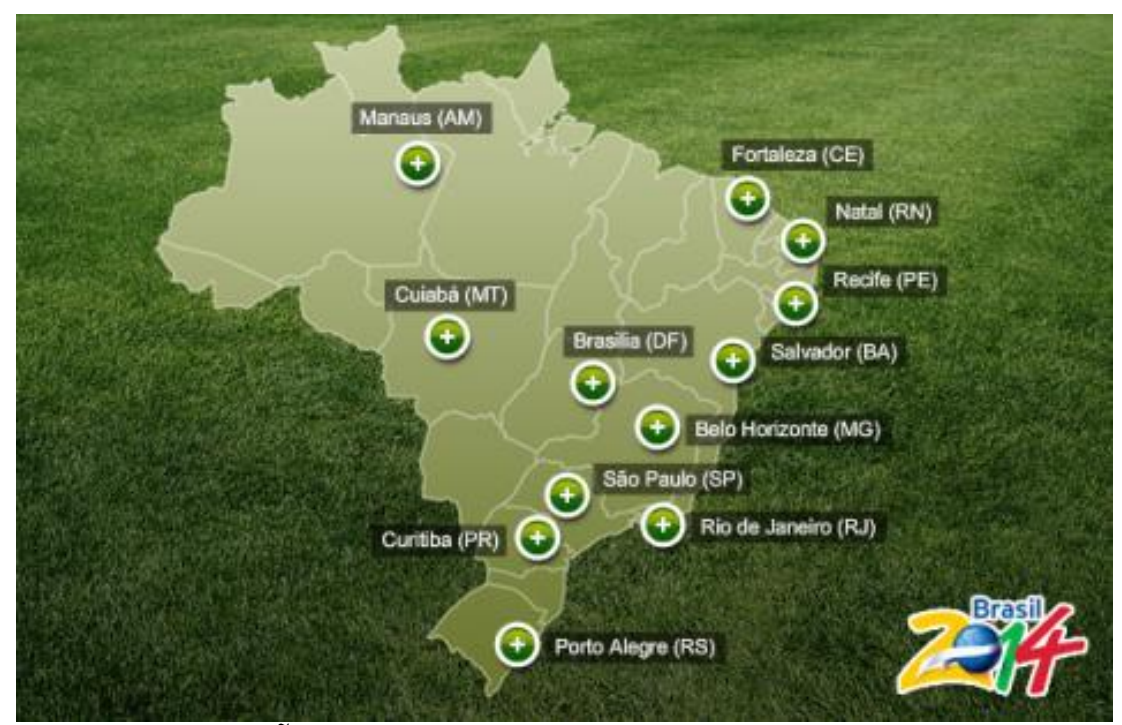

FIGURA 1 - DISTRIBUIÇÃO DAS CIDADES-SEDE DA COPA DO MUNDO 2014. Fonte: MAPA DA COPA (2012).

Pode-se degustar a mistura das culturas portuguesa e africana nas mesas baianas e mineiras; a influência indígena nas mesas amazonenses e mato-grossenses; a influência europeia marcante nas mesas paranaenses e gaúchas; e a miscigenação culinária das grandes metrópoles São Paulo e Rio de Janeiro. Técnicas de preparo curiosas, criadas a partir da fusão de tantas outras ou pela própria necessidade de criar soluções diante da falta de equipamentos, manipulam ingredientes nativos $\mathrm{e}$ "importados" 3 , criando receitas tipicamente brasileiras e versões locais dos pratos de imigrantes.

\footnotetext{
${ }^{2}$ Após uma extensa pesquisa, o Ministério do Turismo (MTUR) definiu 65 destinos indutores no país inteiro. Um destino indutor é aquele que possui um conjunto de atrativos qualificados e infraestrutura adequada, e que se destaca em sua região turística. Estes destinos receberão dos técnicos do MTUR orientação e capacitação para alcançar um nível de competitividade internacional e contribuir para o desenvolvimento da região em que se inserem. (SEBRAE, FGV, MTUR, 2008).
${ }^{3}$ Alguns dos ingredientes tidos como tipicamente brasileiros foram, na verdade, trazidos para o Brasil há centenas de anos. Dentre os vários exemplos pode-se citar a cana de açúcar (originária do sudeste asiático e trazida para o Brasil durante o período da colonização pelos portugueses) e o café (de origem africana, trazido para o Brasil no século XVIII). (CASCUDO, 2004).


Equipamentos e utensílios também mostram a variedade da cozinha brasileira: fogões à lenha, moquéns, panelas de barro, panelas de ferro, panelas esmaltadas, colheres de pau e até mesmo folhas de bananeira são utilizados para criar sabores regionais. Dentre outros elementos característicos da gastronomia brasileira, que a tornam tão rica e atrativa, pode-se citar (baseado em CASCUDO, 2004 e em FERNANDES, 2009):

a) A onipresença da mandioca: herança indígena, a mandioca aparece sob a forma de diferentes farinhas (com muitos tipos de ralagens e torras) que acompanham diversos pratos, tais como caldeiradas ${ }^{4}$ e a brasileiríssima feijoada; ou ainda como ingrediente de pratos doces e salgados, como a paçoca de pilão ${ }^{5}$, a maniçoba ${ }^{6}$ e o bolo de puba $^{7}$;

b) O uso de cereais como arroz (o acompanhamento preferido dos brasileiros), o milho e os diferentes tipos de feijão (desde o feijão preto, tradicional da feijoada; até o feijão fradinho, ingrediente básico do acaraje ${ }^{8}$ ) em receitas presentes em todo o país;

c) A riqueza de vegetais: o país possui grande diversidade de verduras, legumes e frutas, sendo que estas merecem um destaque especial. A exuberância da floresta amazônica (com frutas como o açaí, cupuaçu e graviola) e do litoral nordestino (cajá, mangaba, e umbu, dentre tantos outros exemplos) fornece frutas com sabores tão característicos que muitas vezes são desconhecidas in natura por muitos brasileiros;

d) Utilização de gorduras que deixam um sabor bastante específico nas preparações, como é o caso da banha de porco ${ }^{9}$, do azeite de dendê ${ }^{10}$ e da manteiga de garrafa $^{11}$;

\footnotetext{
${ }^{4}$ Cozido de peixe - geralmente salgado - ou frutos do mar preparado em todo o país. Os temperos variam regionalmente, e podem incluir coentro, cheiro verde, cebola, tomate, dentre outros. (FERNANDES, 2009).

${ }^{5}$ Carne de sol batida no pilão com mandioca e temperos, como cebola e manteiga de garrafa. (FERNANDES, 2009).

${ }^{6}$ Também conhecida como feijoada paraense, é feita com folhas de mandioca moída e cozidas para que o ácido cianídrico seja eliminado. A estas folhas são acrescidas carne de porco (talvez carne bovina) e outros ingredientes. (FERNANDES, 2009).

${ }^{7}$ Bolo feito com puba, massa de mandioca fermentada, que é misturada com ovos, leite de coco e açúcar, dentre outros ingredientes. (FERNANDES, 2009).

${ }^{8}$ De influência africana, é um bolinho feito com feijão fradinho cozido e moído, cebola e sal, frito em azeite de dendê e servido geralmente com vatapá. O vatapá, por sua vez de consistência cremosa, é um prato de influência africana feito geralmente com farinha de rosca, pimenta, amendoim, leite de coco, cebola, tomate e outros ingredientes, como o camarão. (CASCUDO, 2004).
} 
e) Uso de diferentes proteínas animais: as regiões sul e centro-oeste garantem a oferta de carne bovina, consumida em todo país e indispensável para o tradicional churrasco gaúcho. Galinhas e porcos são criados no país inteiro, estando presentes nas mesas de muitos brasileiros (o consumo de carne de porco é notadamente tradicional nas regiões sul e sudeste). A costa brasileira fornece diferentes peixes de água salgada, bem como uma diversidade de frutos do mar significativa. O centro-oeste e o norte oferecem uma grande variedade de peixes de água doce. De consumo menos expressivo, mas ainda presente nas mesas regiões, pode-se citar a carne de jacaré criada em cativeiro para fins culinários na região centro-oeste, a criação de búfalos na região norte (mais especificadamente no Pará) e o uso de carne de bode no agreste brasileiro;

f) Diversidade de bebidas típicas: a mais brasileira das bebidas é a cachaça, produzida em todo o país, aromatizada das mais diferentes formas (inclusive com banana) e usada para a produção de "batidas" e da famosa caipirinha ${ }^{12}$ (primeiro coquetel brasileiro a ser incluído no IBA - International Barmen Association) (FERNANDES, 2009) e suas variações com as mais diferentes frutas. Nos estados com influência gaúcha (além do Rio Grande do Sul, Santa Catarina, Paraná, Mato Grosso e Mato Grosso do Sul) é comum o consumo de chimarrão e sua variação paraguaia, o tereré $^{13}$. Bebida cuja técnica de produção foi trazida pelos imigrantes italianos, o vinho é produzido em algumas regiões do país, com destaque para a Serra Gaúcha no Rio Grande do Sul e o Vale do Rio São Francisco na Bahia e Pernambuco, regiões que têm conseguido reconhecimento internacional, principalmente com a produção de

\footnotetext{
${ }^{9}$ A banha de porco durante muito tempo foi utilizada como meio de conservação para carnes e outros alimentos (a expressão "carne de lata" diz respeito à carne de porco conservada desta forma). Associada à culinária caipira, é consumida principalmente nos estados de Minas Gerais e no interior de São Paulo. (CASCUDO, 2004).

${ }^{10}$ Também conhecido como óleo de palma, é produzido a partir do fruto do Dendezeiro, uma espécie de palmeira. Bastante comum no nordeste brasileiro, quase não é consumido nas outras regiões. (GOMENSORO, 1999).

${ }^{11}$ Obtida a partir do cozimento do creme de leite bovino até que toda a água seja evaporada, é uma espécie de manteiga que se mantém líquida em temperatura ambiente. Produto típico do nordeste brasileiro. (GOMENSORO, 1999).

${ }^{12}$ Caipirinha é, por definição, uma bebida feita com limão em rodelas, cachaça, gelo e açúcar. Assim, uma caipirinha de morango, por exemplo, não se constitui em uma caipirinha propriamente dita. Nasceu no interior de São Paulo como um derivado de remédios populares, caseiros, à base de cachaça, com limão, alho, mel e ervas. (GOMENSORO, 1999).

${ }^{13}$ Bebida semelhante ao chimarrão, mas elaborada com água fria. (FERNANDES, 2009).
} 
espumantes (deve-se mencionar que o vinho de menor qualidade, também conhecido como "vinho de mesa", é produzido em diversas localidades brasileiras). A cerveja, uma das bebidas alcoólicas mais consumidas no país, tem seu consumo atrelado às marcas produzidas em escala industrial - já que a produção de cervejas artesanais é bastante tímida. Transformado em refrigerante, o guaraná também aparece em diversos sucos, principalmente por seu valor energético. Não se pode deixar de mencionar ainda a variedade de sucos e de bebidas bastante regionais, como é o caso da cajuína ${ }^{14}$;

g) Riqueza da doçaria: de influência portuguesa na região nordeste e no sudeste, e de influência alemã na região sul, a doçaria brasileira é feita a partir de inúmeros ingredientes, dentre eles: açúcar, ovos, frutas, cereais como milho e arroz, mandioca, dentre outros. Como representantes, tem-se geleias ${ }^{15}$, frutas cristalizadas, doces de leite, de coco e de abóbora, quindins, cocadas, bolos complexos (como o Souza Leão ${ }^{16}$ ), dentre outros;

h) Diversidade de pratos típicos: sintetizando ingredientes, técnicas de preparo e outras tradições, o Brasil possui uma série de pratos regionais emblemáticos ${ }^{17}$. Além da feijoada, principal referência do estrangeiro sobre a gastronomia nacional, pode-se destacar: no sul, o Churrasco ${ }^{18}$ e o Barreado $^{19}$; no sudeste, a Moqueca capixaba ${ }^{20}$, o

\footnotetext{
${ }^{14}$ Bebida não alcoólica produzida a partir do caju é bastante comum no nordeste brasileiro, com destaque especial para a produção do estado do Piauí. (CASCUDO, 2004).

${ }^{15}$ Deve-se mencionar que as geleias nasceram da necessidade de aproveitar e preservar as frutas para seu uso durante o inverno. As técnicas trazidas por portugueses e posteriormente italianos e alemães se difundiram no Brasil e deram origem às mais diferentes geleias. (FERNANDES, 2009).

${ }^{16}$ Foi considerado patrimônio cultural e imaterial do Estado de Pernambuco pela Lei $\mathrm{n}^{\mathrm{o}} 357$ de 2007, é feito com várias gemas (aproximadamente 10), massa de mandioca e leite de coco, dentre outros ingredientes. (FERNANDES, 2009).

${ }^{17}$ Um prato emblemático, para Maria Eunice Maciel (1995) é aquele possuidor de um sentido unificador e marcador de identidade para um determinado grupo.

${ }^{18}$ Embora vários cortes de carne sejam utilizados para fazer churrasco em todo o país, é válido mencionar que o churrasco considerado por muitos o mais tradicional é o de costela bovina, temperada apenas com sal grosso. (FERNANDES, 2009).

${ }^{19}$ Principal prato típico do estado do Paraná. Apesar de ser um prato litorâneo, é feito à base de carne de boi de segunda, cozida exaustivamente com toucinho (bacon), cominho e folhas de louro em uma panela de barro lacrada com uma folha de bananeira e uma pasta feita com água e farinha de mandioca. (GIMENES, 2013).

${ }^{20}$ Feita com peixes, coentro, cebola, tomate e outros ingredientes, tem como principal diferencial em relação à moqueca baiana não ser feita com azeite de dendê nem com leite de coco. É típica do estado do Espírito Santo. (FERNANDES, 2009).
} 
Tutu de feijão ${ }^{21}$ e o Azul Marinho ${ }^{22}$; no nordeste, o Arroz de Cuxá ${ }^{23}$, a Moqueca baiana $^{24}$, o Sarapatel ${ }^{25}$; no norte, o Tacacá ${ }^{26}$; no centro-oeste, o Caldinho de Piranha ${ }^{27}$ e o Arroz com Pequi ${ }^{28}$.

Estas iguarias - e tantas outras - são ofertadas em bares, restaurantes e similares, em feiras e festas gastronômicas e até mesmo em mercados públicos. O potencial turístico de muitas, inclusive, já é explorado a partir de rotas e roteiros turísticos organizados em todo país a partir do Programa de Regionalização do Turismo Roteiros do Brasil (2012e), promovido pelo Ministério do Turismo. Contudo, pensando na dimensão de um evento como a Copa do Mundo de Futebol da FIFA 2014, torna-se evidente a necessidade de uma articulação maior deste potencial com outros atrativos, bem como sua efetiva qualificação e divulgação, para que haja um fortalecimento efetivo do mercado gastronômico brasileiro.

\footnotetext{
${ }^{21}$ Feijão cozido e refogado preparado com bacon, cebola e outros temperos, além da farinha (que pode ser de mandioca ou de milho). (FERNANDES, 2009).

${ }^{22}$ Prato caiçara associado principalmente ao litoral de São Paulo é feito com peixes de água salgada cozidos com temperos e banana verde, o que confere a cor que batiza o prato. (FERNANDES, 2009).

${ }^{23}$ Típico do estado do Maranhão é um arroz preparado com folhas de vinagreira (uma espécie de arbusto com gosto azedo), camarão seco e farinha de mandioca. (FERNANDES, 2009).

${ }^{24}$ Feita com peixes e/ou frutos do mar, coentro, cebola, tomate e outros ingredientes, tem como características distintivas o uso do azeite de dendê e do leite de coco. (FERNANDES, 2009).

${ }^{25}$ Típico do nordeste brasileiro, este prato à base de vísceras picadas cozidas com temperos pode ser preparado com porco, carneiro ou bode. (FERNANDES, 2009).

${ }^{26}$ Típico da região norte, é um caldo servido muito quente em cuias preparado com tucupi (caldo de mandioca brava que é cozido intensivamente), camarão seco e jambu (uma erva que dá a sensação de dormência na língua), dentre outros ingredientes. (FERNANDES, 2009).

${ }^{27}$ O famoso peixe carnívoro é cozido, tem sua carne separada, desfiada (algumas vezes batida no liquidificador) e novamente cozida com temperos. Segundo algumas crendices populares, é um alimento afrodisíaco. Típico da região centro-oeste. (FERNANDES, 2009).

${ }^{28}$ Típico da região centro-oeste, o pequi é um fruto típico do Cerrado, que também pode ser consumido puro ou cozido com outros alimentos (além do arroz, é muito comum prepará-lo com frango). Uma peculiaridade é a quantidade de espinhos muito finos que possui e que demandam cuidado em seu preparo. (FERNANDES, 2009).
} 


\subsection{INICIATIVAS VOLTADAS PARA A QUALIFICAÇÃO, PROMOÇÃO E DIVULGAÇÃO DA GASTRONOMIA BRASILEIRA}

Até o final do ano de 2013, poucas ações efetivas voltadas à qualificação, promoção e divulgação da gastronomia brasileira foram efetivadas. No âmbito da qualificação, a maior iniciativa foi o Programa Bem Receber Copa.

A partir da captação da Copa do Mundo de Futebol da FIFA 2014 para o Brasil, o Ministério do Turismo definiu 4 eixos de atuação profissional: promoção e imagem, requalificação do parque hoteleiro, infraestrutura turística e qualificação profissional. (MINISTÉRIO DO TURISMO, 2012c). Para atender à última questão foi lançado em 2011 o Programa Bem Receber Copa, um programa de qualificação profissional do Ministério do Turismo em parceria com entidades do setor que tem como objetivo qualificar o setor turístico nacional segundo padrões internacionais de qualidade (SINAENCO, 2011; MINISTÉRIO DO TURISMO, 2012c).

Tendo como slogan "O sucesso do Brasil na Copa está nas suas mãos", o Programa Bem Receber Copa foi organizado em seis segmentos, dentre eles o de alimentação fora do lar. (MINISTÉRIO DO TURISMO, 2012c). As instituições parceiras para as ações nesse segmento são a ABRASEL (Associação Brasileira de Restaurantes e Similares) e a FBHA (Federação Brasileira de Hospedagem e Alimentação), sendo a principal iniciativa o "Bem receber Copa - Bares e Restaurantes", que tem como objetivo principal transformar bares e restaurantes em pontos de apoio ao turista, além de qualificar os estabelecimentos a partir dos eixos de hospitalidade, gastronomia segura (inclusive em termos de manipulação de alimentos) e informações básicas sobre o destino. (SINAENCO, 2011).

O "Bem Receber Copa" tinha como objetivo capacitar até 2013, por meio de ações presenciais e à distância, 306 mil trabalhadores que atenderiam o turista na linha de frente em todo o país. Contudo, por recomendação do Tribunal de Contas da União (TCU) devido a irregularidades encontradas, o Ministério do Turismo suspendeu em setembro de 2011 a execução e o repasse de recursos dos convênios celebrados com entidades privadas e sem fins lucrativos com o objetivo de qualificação profissional, em especial os recursos destinados ao "Bem Receber Copa". (SINAENCO, 2012). Até o 
fechamento deste artigo, ainda não estavam disponíveis relatórios sobre os resultados mesmo que parciais - alcançados por esta ação.

Do ponto de vista da divulgação, pode-se mencionar algumas ações, com destaque para a publicação 'Aromas, cores \& sabores do Brasil' (MINISTÉRIO DA CULTURA, 2013):

a) O Movimento Brasil Sabor:

Trata-se de uma iniciativa de divulgação da gastronomia brasileira para o público interno, fruto de uma ação conjunta da ABRASEL, do SEBRAE (Agência de Apoio ao Empreendedor e ao Pequeno Empresário) e do Ministério do Turismo tendo como objetivo valorizar e promover a gastronomia brasileira como um grande diferencial competitivo para o país. (BRASIL SABOR, 2012). Dentre suas ações estão a realização de um evento anual desde 2006 chamado Festival Brasil Sabor, no qual, por um período limitado, os estabelecimentos participantes no país inteiro oferecem, a preços diferenciados, um prato criado para o evento, que consiste em uma especialidade da casa que também leva em consideração as características e as tradições de cada região ou estado. (BRASIL SABOR, 2012).

b) Caminhos do sabor - a união faz o destino

Trata-se de um projeto desenvolvido em conjunto pelo Ministério do Turismo e a Abrasel tendo como objetivo desenvolver roteiros gastronômicos que apresentem a gastronomia como um instrumento revelador da cultura de um povo e um diferencial competitivo para o turismo. (MINISTÉRIO DO TURISMO, 2012b). Desde 2004 três roteiros foram mapeados e deram origem a publicações específicas: "A Estrada Real" (desenvolvido entre os estados de Minas Gerais, São Paulo e Rio de Janeiro), "A Rota dos Tropeiros" (que reproduz o histórico caminho que seguia de Viamão (RS) até Sorocaba (SP)) e "Do doce ao Sal" (que envolve localidades do norte e do nordeste do país). (MINISTÉRIO DO TURISMO, 2012b). 
c) Termo de cooperação técnica entre a Embratur (Instituto Brasileiro de Turismo) e a Associação Brasil à Mesa

Visando a promoção internacional da gastronomia brasileira, assinado em novembro de 2012. A Associação Brasil à Mesa foi criada em 2012, motivada por um protesto contra a orientação de que hotéis para serem classificados como cinco estrelas deveriam ter, obrigatoriamente, um restaurante de comida internacional. (UOL, 2012). Esta Associação tem como objetivo pensar estratégias e ações que valorizam os insumos brasileiros, que preservem a cultura gastronômica brasileira, e incentivem a pesquisa e auxiliam no desenvolvimento de pequenos produtores e dos profissionais do setor; além de contribuir para a promoção da gastronomia brasileira no país e no exterior. (UOL, 2012). Esta Associação também participa do Grupo de Turismo Gastronômico (GTG), criado também em 2012 pelo Ministério do Turismo, cujos objetivos são, dentre outros, estabelecer uma curadoria gastronômica para o evento Salão de Turismo, implementar um selo de qualidade para o setor de alimentação e ampliar o Cadastur da área. Estas iniciativas ainda não possuem linhas de atuação definidas, mas representam um importante esforço no sentido de buscar um aproveitamento turístico mais adequado para o patrimônio gastronômico brasileiro. (MINISTÉRIO DO TURISMO, 2012b).

d) Publicação "Aromas, cores e sabores do Brasil' (MINISTÉRIO DA CULTURA, 2013):

O único material específico sobre gastronomia e disponibilizado on line da página oficial do evento no Brasil (www.copa2014.gov.br) é uma iniciativa do Ministério da Cultura. Trata-se de uma publicação bilíngue (português/inglês) com 55 páginas e que tem como público alvo jornalistas brasileiros e estrangeiros, mencionados na apresentação do material: “[...] Por isso, sejam todos bem-vindos, jornalistas brasileiros e estrangeiros, a descobrir o Brasil das mais variadas formas possíveis". (MINISTÉRIO DA CULTURA, 2013, p. 2).

O material apresenta a gastronomia brasileira como uma síntese da construção histórica e da diversidade humana e geográfica do país. Com o objetivo de apresentar o patrimônio gastronômico a estes profissionais formadores de opinião, estabelecendo a 
gastronomia como uma síntese de construção histórica brasileira e diversidade geográfica e humana:

O Brasil é um país de dimensões continentais, tem relevos dos mais variados, com regiões de proximidade ou grande distância do mar, com florestas de diferentes climas, rios. Também é formado por povos de diferentes origens, vindas de todas as partes do mundo. Tudo isso é possível de ser sentido ao explorarmos nossa gastronomia que foi, ao longo do tempo, sendo construída com nossa diversidade e ao mesmo tempo com nossa integração. (MINISTÉRIO DA CULTURA, 2013, p. 4, grifo nosso).

Nossa tão conhecida feijoada, a cachaça e o queijo minas - ambos reconhecidos também por seu modo de produção típicos, o churrasco, os sorvetes e sucos de inúmeros sabores encontrados pelo Brasil, os peixes, os pratos tropeiros e tantos outros (impossível citar todos) são símbolos de nossa diversidade, geografia, história e de tudo mais que compõe nossa Cultura. Saborear o Brasil é sabê-lo um pouco. (MINISTÉRIO DA CULTURA, 2013, p. 4, grifo nosso).

Com mais de 500 anos de história, a culinária brasileira é resultante de uma grande mistura de tradições, ingredientes e alimentos que foram introduzidos não só pela população nativa indígena como por todas as correntes de imigração que ocorreram no período. (MINISTÉRIO DA CULTURA, 2013, p. 6, grifo nosso).

Cada região do País tem sua peculiaridade, devido às diferenças de clima, relevo, tipo de solo, vegetação e povos habitando uma mesma região. Além disso, o próprio descobrimento do Brasil remete à culinária, já que as caravelas portuguesas desembarcaram aqui em 1500 enquanto navegavam em busca das Índias e suas especiarias. (MINISTÉRIO DA CULTURA, 2013, p. 6, grifo nosso).

Considerando que há apenas duas páginas destinadas à apresentação do material, verifica-se uma preocupação em demarcar a gastronomia nacional (embora o termo culinária também seja utilizado) como uma expressão da cultura miscigenada brasileira, amparada por um patrimônio natural igualmente diversificado. Essa relação entre diversidade gastronômica/diversidade ambiental parece constituir o eixo orientador da divisão interna do próprio material:

QUADRO 1 - DESCRITIVO DAS SEÇÕES DA BROCHURA 'AROMA, CORES \& SABORES DO BRASIL'

\begin{tabular}{|l|l|l|}
\hline & \multicolumn{1}{|c|}{ SEÇÃO } & \multicolumn{1}{c|}{ CONTEÚDO } \\
\hline 1 & Festas Juninas & Breve histórico das Festas Juninas. \\
\hline 2 & Símbolos & $\begin{array}{l}\text { Breve descrição de símbolos das Festas Juninas: fogueira, balões e } \\
\text { quadrilha. }\end{array}$ \\
\hline 3 & $\begin{array}{l}\text { Festejos famosos nas } \\
\text { cidades sede }\end{array}$ & $\begin{array}{l}\text { Breve descritivo das Festas Juninas que ocorrem em Belo Horizonte, } \\
\text { Brasília, Fortaleza, Recife, Rio de Janeiro e Salvador. }\end{array}$ \\
\hline 4 & Receitas típicas & Descritivo das receitas de canjica, quentão e pamonha. \\
\hline
\end{tabular}

Continua... 
...continuação

\begin{tabular}{|l|l|l|}
\hline 5 & $\begin{array}{l}\text { Culinária aliada ao clima } \\
\text { e vegetação }\end{array}$ & $\begin{array}{l}\text { Há uma frase mencionando a relação entre culinária, clima e } \\
\text { vegetação e o restante da página apresenta um breve histórico da } \\
\text { caipirinha e do doce brigadeiro. }\end{array}$ \\
\hline 6 & Bioma Gastronômico & Mapa dos biomas que serão descritos. \\
\hline 7 & Bioma Amazônia & $\begin{array}{l}\text { Indicação de estados abrangidos por este bioma, breve descritivo, } \\
\text { principais ingredientes, pratos típicos e receitas. }\end{array}$ \\
\hline 8 & Bioma Caatinga & $\begin{array}{l}\text { Indicação de estados abrangidos por este bioma, breve descritivo, } \\
\text { principais ingredientes, pratos típicos e receitas. }\end{array}$ \\
\hline 9 & Bioma Cerrado & $\begin{array}{l}\text { Indicação de estados abrangidos por este bioma, breve descritivo, } \\
\text { principais ingredientes, pratos típicos e receitas. }\end{array}$ \\
\hline 10 & Bioma Pantanal & $\begin{array}{l}\text { Indicação de estados abrangidos por este bioma, breve descritivo, } \\
\text { principais ingredientes, pratos típicos e receitas. }\end{array}$ \\
\hline 11 & Bioma Mata Atlântica & $\begin{array}{l}\text { Indicação de estados abrangidos por este bioma, breve descritivo, } \\
\text { principais ingredientes, pratos típicos e receitas. }\end{array}$ \\
\hline 12 & Bioma Pampa & $\begin{array}{l}\text { Indicação de estados abrangidos por este bioma, breve descritivo, } \\
\text { principais ingredientes, pratos típicos e receitas. }\end{array}$ \\
\hline
\end{tabular}

Fonte: Elaborado a partir de MINISTÉRIO DA CULTURA (2013).

Do ponto de vista da organização interna do material, tendo em vista tratar-se de um documento informativo, a opção realizada parece não ter sido a mais adequada. As Festas Juninas abrem o material, sem que seja anunciado que estas são as Festas Populares que acontecem no país durante o megaevento - para jornalistas estrangeiros, essa relação apenas se estabelece ao ler as datas de realização de cada uma das festas mencionadas. Ainda, as seções 'símbolos', 'festejos famosos na cidade sede' e 'receitas típicas' dizem respeito exclusivamente às Festas Juninas, embora sejam apresentadas como itens isolados no sumário.

$\mathrm{Na}$ página 15, há a seção 'Culinária aliada ao clima e vegetação', onde, esperava-se, deveria constar uma explicação geral adequada de como esta relação entre clima, vegetação e culinária se dá em todo o país. A primeira frase enuncia a abordagem esperada: "Assim como os biomas naturais influenciam as paisagens e a diversidade de fauna e flora, esses mesmos biomas tem características marcantes que influenciam a gastronomia do Brasil” (MINISTÉRIO DA CULTURA, 2013, p. 5). Contudo, o texto continua com a seguinte frase: "Com pratos e ingredientes típicos, algumas receitas são conhecidas e replicadas por todo o País e no mundo. É o caso da caipirinha. Ela surgiu no Século 20, quando a mistura de cachaça, limão, mel [...]”. Terminado um breve histórico da caipirinha, tem início um breve descritivo histórico do doce brigadeiro.

Na sequência, há uma ilustração do mapa do Brasil com os biomas selecionados indicados por cores diferentes. Apesar de ser visualmente atrativo, como não constam as unidades federativas, a figura pouco informa sobre as áreas de abrangência dos biomas. 
Na página 18 os biomas já começam a ser apresentados. Em relação à descrição de cada um dos biomas (vide apêndice 1, com o descritivo completo), tem-se:

No descritivo do Bioma Amazônia o legado indígena é enaltecido, sendo lembrados também outros povos como colonizadores portugueses e também libaneses, japoneses, italianos e nordestinos, que migraram para a região a partir do Ciclo da Borracha. Há a menção desta culinária ser considerada por muitos “[...] o maior exemplo de culinária tipicamente nacional” (MINISTÉRIO DA CULTURA, 2013, p. 18), seus pratos são descritos como mescla "exuberância da floresta tropical e do mar" e a mandioca, destacada como um dos “[...]ingredientes mais importantes na história da alimentação brasileira”, é apontada como oriunda desse bioma: “[...] saiu da Amazônia e ganhou o continente se adaptando aos terrenos locais e recriando suas próprias texturas, cores, aromas e sabores" (MINISTÉRIO DA CULTURA, 2013, p. 18).

O Bioma Caatinga é descrito a partir de sua diversidade climática: a seca e o clima semiárido "[...] imprimem na mesa do sertanejo uma cozinha de perenidade, ligada à conservação dos alimentos, altos teores calóricos e recursos para as constantes jornadas em busca de água” (MINISTÉRIO DA CULTURA, 2013, p. 20), enquanto nas regiões mais próximas do mar "[...] as receitas ganham em diversidade de ingredientes e cores' (MINISTÉRIO DA CULTURA, 2013, p. 20). A presença africana durante o Ciclo da Cana-de-açúcar na região costeira, a influência portuguesa na cozinha maranhense são lembrados nesse descritivo, assim como a carne-de-sol e os pratos feitos com raízes (não há especificação). Há novamente a menção às Festas Juninas e o destaque para a comida de rua: "não se espante se encontrar vendedores ambulantes pelas ruas de Salvador com trios elétricos vendendo café, bebida típica brasileira, que pode ser tomada a qualquer hora do dia" (MINISTÉRIO DA CULTURA, 2013, p. 20). O texto ainda afirma que os pratos são "carregados de sabor" e que a "criatividade é marcante na região" (MINISTÉRIO DA CULTURA, 2013, p. 20).

O texto do Bioma Cerrado é destinado principalmente por caracterizar a mata da região e indicá-la como cenário de alguns momentos históricos. A menção à gastronomia local relaciona a importância da pecuária na região, colocando-a como justificativa da “[...] a grande preferência da população do Centro-Oeste por carnes bovina, caprina e suína, e a forte presença indígena liderou a preferência regional por raízes”. (MINISTÉRIO DA CULTURA, 2013, p. 24). 
O descritivo do Bioma Pantanal é o mais sucinto e genérico: “[...] é a maior planície de inundação contínua do planeta. Dessas formações, chegam à mesa do pantaneiro uma seleção de ingredientes que geram receitas bem particulares da região" (MINISTÉRIO DA CULTURA, 2013, p. 26).

O Bioma Mata Atlântica tem em sua descrição a ênfase na mescla de culturas nacionais e estrangeiras. Segundo a publicação:

\begin{abstract}
Até o Século 19, a cozinha do Sudeste era essencialmente influenciada pelas origens portuguesas, indígenas e africanas. Alimentos simples, como raízes, carnes, grãos e vegetais foram disseminados por todo o território do Sudeste, o que fez com que a gastronomia de cada estado se tornasse bastante similar em ingredientes e no preparo dos alimentos. A exceção é a culinária capixaba que, por sua proximidade com o Nordeste e grande área litorânea, tem uma forte presença de peixes e frutos do mar nos pratos do dia-a-dia. Após a chegada de imigrantes japoneses, libaneses, sírios, italianos e espanhóis, a diversidade gastronômica, sobretudo em São Paulo, aumentou. (MINISTÉRIO DA CULTURA, 2013, p. 27).
\end{abstract}

A mistura étnica também ganha destaque no descritivo do Bioma Pampa, onde consta: "a mistura étnica ocorrida na região Sul resultou em uma culinária completamente diferente do resto do país, com a presença ainda mais forte da cozinha italiana, alemã, além das já presentes portuguesa e espanhola" (MINISTÉRIO DA CULTURA, 2013, p. 30). O churrasco, as massas, a polenta, o frango, o cultivo das vinhas e o fabrico de vinho, além do consumo de raízes e grãos são mencionados. (MINISTÉRIO DA CULTURA, 2013).

Observa-se que os textos reforçam a ideia da diversidade gastronômica pautada em heterogeneidade étnica e ambiental enunciadas na apresentação do material, e o uso de adjetivos como "exuberante", "saboroso", "colorido", "criativo" são bastante utilizados em todo o texto. Seguindo a lógica de mostrar um Brasil gastronômico múltiplo, a apresentação da brochura já estabelece:

É muito difícil estabelecer apenas um prato típico brasileiro. A unanimidade nacional é, talvez, o arroz e o feijão, cujo preparo varia conforme a região. No entanto, a mistura de dois ingredientes tão comuns na mesa do brasileiro, apesar de característica, ainda não é suficiente para resumir toda a complexidade e a riqueza da culinária nacional. (MINISTÉRIO DA CULTURA, 2013, p. 6). 
Como mencionado no quadro 1 , o descritivo de cada bioma indica também quais os principais ingredientes e os pratos típicos locais, além de indicar algumas receitas. Estas informações estão sintetizadas a seguir:

QUADRO 2 -DESCRITIVO DOS BIOMAS - PUBLICAÇÃO 'AROMAS, CORES \& SABORES DO BRASIL'

\begin{tabular}{|c|c|c|c|c|}
\hline & Bioma & Principais ingredientes & Pratos típicos & $\begin{array}{l}\text { Receitas } \\
\text { indicadas }\end{array}$ \\
\hline 1 & $\begin{array}{l}\text { Bioma } \\
\text { Amazônia }\end{array}$ & $\begin{array}{l}\text { Mandioca, cupuaçu, açaí, } \\
\text { Pirarucu, Filhote, urucum (açafrão } \\
\text { brasileiro), jambú, guaraná, } \\
\text { Tucunaré, castanha--do-Pará, } \\
\text { tucupi, farinhas; queijo do } \\
\text { Marajó, pimentas; feijões. }\end{array}$ & $\begin{array}{l}\text { Pato no Tucupi, Tacacá (caldo } \\
\text { quente servido com tucupi, camarão } \\
\text { seco, jambú e goma de tapioca), } \\
\text { Maniçoba (a feijoada paraense - } \\
\text { folhas da mandioca cozidas por sete } \\
\text { dias e servidas com carne suína), } \\
\text { Pirarucu de casaca (pescado com } \\
\text { farinha). }\end{array}$ & $\begin{array}{l}\text { Pato no } \\
\text { Tucupi, } \\
\text { Tambaqui } \\
\text { assado. }\end{array}$ \\
\hline 2 & $\begin{array}{l}\text { Bioma } \\
\text { Caatinga }\end{array}$ & $\begin{array}{l}\text { Feijão-fradinho, mandioca, milho, } \\
\text { manteiga-de-garrafa, abóboras, } \\
\text { queijo de coalho, queijo manteiga, } \\
\text { requeijão do sertão; carnes } \\
\text { curadas, rapadura; mel de } \\
\text { engenho, castanha de caju, frutas; } \\
\text { carnes de ovinos, caprinos e } \\
\text { bovinos; arroz; feijões; farinhas. }\end{array}$ & $\begin{array}{l}\text { Buchada de bode, carne de sol com } \\
\text { pirão de coalho, paçoca de carne } \\
\text { seca, baião de dois, tapioca; canjica, } \\
\text { pamonha; bolos; escondidinho; } \\
\text { tapioca; bolos; caldo de mocotó. }\end{array}$ & $\begin{array}{l}\text { Tapioca, } \\
\text { Baião de } \\
\text { dois, Bolo } \\
\text { Souza Leão, } \\
\text { Acarajé. }\end{array}$ \\
\hline 3 & $\begin{array}{l}\text { Bioma do } \\
\text { Cerrado }\end{array}$ & $\begin{array}{l}\text { Pequi, couve, ora-pro-nóbis, } \\
\text { quiabo, mandioca, carnes curadas, } \\
\text { carne suína e bovina, milho, } \\
\text { frutas, pimentas, farinhas, } \\
\text { embutido;; arroz; feijões; } \\
\text { cachaça; baru. }\end{array}$ & $\begin{array}{l}\text { Arroz com pequi, picadinho com } \\
\text { quiabo, empadão goiano, vaca } \\
\text { atolada; feijão tropeiro mineiro; } \\
\text { frango com quiabo; refogado de } \\
\text { milho verde; tutu de feijão; } \\
\text { torresmo. }\end{array}$ & $\begin{array}{l}\text { Risoto do } \\
\text { Cerrado, } \\
\text { Empadão } \\
\text { Goiano. }\end{array}$ \\
\hline 4 & $\begin{array}{l}\text { Bioma } \\
\text { Pantanal }\end{array}$ & $\begin{array}{l}\text { Carne de jacaré, bovina e caprina; } \\
\text { mandioca; pescados; frutas. }\end{array}$ & $\begin{array}{l}\text { Caribéu (refogado de carne seca e } \\
\text { mandioca); Chipa frita (bolinho frito } \\
\text { de queijo curado e polvilho); } \\
\text { furrundu (doce de mamão verde e } \\
\text { rapadura); Pacu assado; caldo de } \\
\text { piranha. }\end{array}$ & $\begin{array}{l}\text { Caldo de } \\
\text { piranha. }\end{array}$ \\
\hline 5 & $\begin{array}{l}\text { Bioma } \\
\text { Mata } \\
\text { Atlântica }\end{array}$ & $\begin{array}{l}\text { Arroz, feijão, carnes curadas, } \\
\text { palmito, mandioca, banana, } \\
\text { batata, polvilho, coco, frutas; } \\
\text { cachaça; embutidos; pescados de } \\
\text { rio e mar; mariscos; carne bovina, } \\
\text { caprina e ovina. }\end{array}$ & $\begin{array}{l}\text { Acarajé, cuscuz, cocada, camarão } \\
\text { no jerimum; virado paulista, } \\
\text { moqueca capixaba, feijoada, } \\
\text { picadinho; doce de leite; pão de } \\
\text { queijo; tapioca; cartola; bolo de } \\
\text { rolo; bobo de camarão; bolinho de } \\
\text { arroz; brigadeiro; goiabada com } \\
\text { queijo de Minas; caipirinha. }\end{array}$ & $\begin{array}{l}\text { Feijão } \\
\text { tropeiro, } \\
\text { Feijoada, } \\
\text { Cuscuz } \\
\text { paulista. }\end{array}$ \\
\hline 6 & $\begin{array}{l}\text { Bioma } \\
\text { Pampas }\end{array}$ & $\begin{array}{l}\text { Carne bovina e caprina; farinha de } \\
\text { milho, erva-mate. }\end{array}$ & $\begin{array}{l}\text { Sopa de capelete; galeto assado; } \\
\text { churrasco; sagu ao vinho tinto; } \\
\text { barreado; arroz de carreteiro. }\end{array}$ & $\begin{array}{l}\text { Sagu com } \\
\text { vinho, } \\
\text { Arroz } \\
\text { carreteiro, } \\
\text { Barreado. }\end{array}$ \\
\hline
\end{tabular}

Fonte: elaborado a partir de Ministério da Cultura (2013).

A iniciativa de divulgar os principais ingredientes e pratos típicos locais cumpre a iniciativa de informar e divulgar a gastronomia brasileira. A limitação, contudo, reside 
no fato de que muitos ingredientes são conhecidos apenas regionalmente (e desconhecidos por muitos brasileiros), além de não possuírem tradução. Por se tratar de um material de poucas páginas, que privilegia a apresentação gráfica, não foram inseridas notas explicativas, que poderiam elucidar um pouco os termos ou as características dos ingredientes mencionados. No que se refere aos pratos típicos, as escolhas são representativas (e muitas delas já mencionadas na revisão bibliográfica que abre o item 3 deste trabalho), havendo surpresa apenas pela inclusão do Risoto do Cerrado, que é pouco tradicional se comparado aos demais.

De maneira geral, esta publicação é uma iniciativa relevante, ricamente ilustrada, com linguagem gráfica moderna e redação clara e objetiva. Contudo, considera-se que a organização interna das informações e o conteúdo de algumas partes (notadamente 'Culinária aliada ao clima e vegetação') não tem um propósito claro, perdendo-se, assim, um importante espaço para a divulgação de outras informações relevantes.

\section{CONSIDERAÇÕES FINAIS}

Megaeventos, por suas características e dimensões, são captados com o objetivo de dinamizar a economia, atraindo investimentos e gerando benefícios permanentes para as localidades em que acontecem. As projeções de visitantes (domésticos e estrangeiros) associados à Copa do Mundo de Futebol da FIFA 2014 evidenciam este megaevento como uma oportunidade única para a divulgação do patrimônio gastronômico nacional. A utilização adequada deste patrimônio pode fortalecer a oferta turística e criar uma marca distintiva para a localidade, principalmente quando associada ao contexto do turismo cultural. A diversidade do país nesse setor é de grande amplitude, como demonstra essa breve revisão.

Até a finalização deste artigo, em novembro de 2013, poucas ações efetivas de divulgação estavam em andamento. A brochura 'Aromas, cores \& sabores do Brasil' foi uma iniciativa relevante, mas algumas características do material (conteúdos, divisão interna, mapa dos biomas) poderiam ter sido desenvolvidas de forma mais adequada. E, tendo em vista a inexistência de relatórios parciais, outras ações como o Programa Bem 
Receber Copa não podem ser avaliadas por enquanto. Será preciso aguardar o término deste megaevento para que se consiga analisar os efeitos e repercussões imediatas geradas por ele, bem como os efeitos relacionados à geração de fluxos turísticos a médio e longo prazo. De qualquer forma, constata-se que os esforços voltados para a divulgação do patrimônio gastronômico brasileiro foram mínimos, deixando-se passar, assim, uma grande oportunidade de fortalecê-lo como um atrativo turístico diferencial.

\section{REFERÊNCIAS}

BRASIL SABOR. Apresentação. Disponível em:

<http://www.brasilsabor.com.br/por/>. Acesso em: 11/11/2012.

BRILLAT-SAVARIN, J.-A. A fisiologia do gosto. São Paulo: Cia das Letras, 1999.

CASCUDO, L. C. História da alimentação no Brasil. Global: São Paulo, 2004.

CHIAS, J. El negocio de la felicidad. Madrid: Pearson Educación, 2005.

EJARQUE, J. Destination marketing: la nuova frontiera della promocommercializzazione turística. Milano: Hoepli, 2009.

FERNANDES, C. Viagem gastronômica pelo Brasil. 9. ed. São Paulo: SENAC, 2009.

FIELDS, K. Demand for the gastronomy tourism product: motivational factors. In: HJALAGER, A.M.; RICHARDS, G. (org). Tourism and gastronomy. Tourism and gastronomy. New York: Routledge, 2002, p. -50.

GÂNDARA, J. M. G.; GIMENES, M. H. S. G.; MASCARENHAS, R. G. T. Reflexões sobre o turismo gastronômico na perspectiva da sociedade dos sonhos. In: PANOSSO NETTO, A.; ANSARAH, M. G. dos R. (org.). Segmentação do mercado turístico estudos, produtos e perspectivas. Barueri: Manole, 2009.

GIMENES-MINASSE, M. H. S. G. Cozinhando a tradição - festa, cultura, história e turismo no litoral paranaense. Curitiba: UFPR, 2013.

GOMENSORO, M. L. Pequeno dicionário de gastronomia. Rio de Janeiro: Objetiva, 1999.

HALL, R.; MITCHELL, R.; SHARPLES, L. Consuming places: the role of food, wine and tourism in regional development. In: HALL, C. M.; SHARPLES, L.; MITCHELL, R.; MACIONIS, N.; CAMBOURNE, B. (org.). Food tourism around the world development, management and markets. Burlington: Elsevier, 2003, p. 25-59. 
MACIEL, M. E. Churrasco à gaúcha. In: Horizontes Antropológicos - Comida, Porto Alegre, 2 (4), p. 34-48, 1995.

MAPA DA COPA. Disponível em: <http://www.guiadacopa.net/2014/noticias-dacopa/83-diversos/908-mapa-da-copa-2014>. Acesso em: 10/11/2012.

MINISTÉRIO DA CULTURA. Aromas, cores \& sabores do Brasil. Disponível em: <http://www.copa2014.gov.br/sites/default/files/livreto_web17062013.pdf>. Acesso em: 10/11/2013.

MINISTERIO DO TURISMO/MTUR. Marcos conceituais do Turismo. Brasília: Ministério do Turismo, 20[?]. Disponível em:

<http://www.turismo.gov.br/export/sites/default/turismo/o_ministerio/publicacoes/down loads_publicacoes/Marcos_Conceituais.pdf>. Acesso em: 10/11/2012a.

MTUR de olho em nossa gastronomia. Disponível em:

<http://www.turismo.gov.br/turismo/noticias/todas_noticias/20120404-1.html>. Acesso em: 10/11/2012b.

Bem receber Copa - conheça o programa. Disponível em:

<http://sv.www5.fgv.br/fgvonline/mtur/programa.asp>. Acesso em: 10/11/2012c.

Portal da Copa. Disponível em: 〈http://www.copa2014.gov.br〉. Acesso em: $10 / 11 / 2012 d$.

.Programa de regionalização do turismo - diretrizes. Disponível em: http://www.turismo.gov.br/export/sites/default/turismo/o_ministerio/publicacoes/downl oads_publicacoes/PROGRAMA_DE_REGIONALIZACAO_DO_TURISMO__DIRETRIZES.pdf Acesso em: 10/11/2012e.

PINE II, J.; GILMORE, J. H. The experience economy. Boston: Harvard School Press, 1999.

RICHARDS, G. Gastronomy: an essencial ingredient in tourism production and consumption? In: HJALAGER, A-M.; RICHARDS, G. (org.). Tourism and gastronomy. London: Routledge, 2002, p. 3-20.

ROCHE, M. Mega events and urban policy. In: Annals of Tourism Research, New York: Pergamon Press, 1994, v. 21, p. 1-19.

SEBRAE, FGV, MTUR. Estudo de competitividade dos 65 destinos indutores do desenvolvimento turístico regional - 2008. Disponível em:

<http://www.dadosefatos.turismo.gov.br/export/sites/default/dadosefatos/outros_estudo s/downloads_outrosestudos/MIOLO_65xdestinosx_revisao4set.pdf $>$. Acesso em: 08/11/2013. 
SINAENCO. Portal 2014 - Turismo suspende convênios do Bem Receber Copa. Disponível em:

<http://www.portal2014.org.br/noticias/8092/TURISMO+SUSPENDE+CONVENIOS+ DO+PROGRAMA+BEM+RECEBER+COPA.html>. Publicado em 26/09/2012, acesso em: $10 / 11 / 2013$.

Portal 2014 - Ministro do Turismo apresenta hoje Programa Bem Receber em SP. Disponível em: <http://www.portal2014.org.br/noticias/2690/MINISTRO+DO+TURISMO+APRESEN TA+HOJE+PROGRAMA+BEM+RECEBER+EM+SP.html> . Publicado em 29/04/2011, acesso em: 30/09/2013.

UOL. Chefs se unem em defesa da gastronomia brasileira em associação que será lançada em maio. Disponível em:

$<$ http://comidasebebidas.uol.com.br/noticias/redacao/2012/04/20/associacao-em-defesada-gastronomia-brasileira-sera-lancado-em-maio-no-festival-gastronomico-de-viscondede-maua.htm>. Publicado em 20/04/2012, acesso em: 08/11/2013.

URRY, J. O olhar do turista: lazer e viagens nas sociedades contemporâneas. São Paulo: Studio Nobel, 2001.

VALLS, J. Gestión de destinos turísticos sostenibles. Barcelona: Gestión 2000, 2004.

Recebido em: 15-11-2013.

Aprovado em: 15-12-2013. 